\title{
DETERMINAN TINGKAT KONSUMSI SANTRI KELAS 6 PONDOK MODERN DARUSSALAM GONTOR KAMPUS 2
}

\author{
Andi Triyawan', Reian Jani' \\ 1,2 Universitas Darussalam Gontor, Indonesia
}

$\triangle$ Corresponding Author:

Nama Penulis: Reian Jani

E-mail: jreian91@gmail.com

\section{Abstract}

The one indicator of economic stability in the pondok modern Darussalam Gontor environment is level of consumption. The purpose of this study was to determine the effect of income and lifestyle on the level of consumption of students of class 6 Pondok Modern Darussalam Gontor campus 2. Data analysis method used in this study is a multiple linear regression analysis method. The results of this study indicate that there is a positive relationship between income and consumption, which is the increase in income, the higher the level of consumption. And there is also a positive relationship between lifestyle and consumption, namely the more lifestyle increases, the higher the level of consumption. The results of this study also obtained that there is a very strong relationship between income and lifestyle towards consumption.

Key words: Consumption; Life Style; Income; Islamic Boarding School

\section{Abstrak}

Salah satu indikator stabilitas perekonomian di lingkungan pondok modern Darussalam Gontor adalah tingkat konsumsi santri. Tujuan dari penelitian ini adalah untuk mengetahui pengaruh pendapatan dan gaya hidup terhadap tingkat konsumsi santri kelas 6 Pondok Modern Darussalam Gontor kampus 2. Metode analisis data yang digunakan dalam penelitian ini adalah metode analisis regresi linier berganda. Hasil dari penelitian ini menunjukkan bahwa terjadi hubungan positif antara pendapatan dengan konsumsi. Semakin tinggi pendapatan maka semakin meningkat tingkat konsumsi. Hubungan positif juga terjadi antara gaya hidup dengan konsumsi, yakni semakin tinggi gaya hidup maka semakin meningkat tingkat konsumsi. Hasil penelitian ini menunjukkan bahwa terjadi hubungan yang sangat kuat antara pendapatan dan gaya hidup terhadap konsumsi.

Kata Kunci: Konsumsi; Gaya Hidup; Pendapatan; Pesantren

\section{PENDAHULUAN}

Politik, social dan ekonomi merupakan tiga bagian terbesar dari kerangka krgiatan mu'amalat (Antonio, 2001). Berdasarkan bagian ekonomi maka dipecah kembali menjadi tiga bagian yaitu konsumsi, 
tabungan/simpanan dan investasi (penanaman modal). Kegiatan konsumsi yang merupakan pokok kegiatan ekonomi menjadi kebutuhan dasar manusia. Oleh karena itu manusia membutuhkan bekal akan dan pikiran untuk menentukan sebuah alternatif terbaik dari beberapa pilihan yangyang tersedia. Sehingga, mereka dapat mencapai tujuan dari konsumsi yang mereka butuhkan.

Perekonomian sebagai salah satu bagian penting dalam pemerintahan sangat dipengaruhi oleh tingkat konsumsi. Konsumsi sangat berpengaruh terhadap stabilitas perekonomian. Peningkatan pada jumlah konsumsi, berdampak pada kegiatan perekonomian negara. Perkembangan zaman menuntun kehidupan manusia untuk semakin berkembang pula. Kebutuhan manusia selain konsumsi juga ada kebutuhan lainnya yaitu kebutuhan tersier dan kebutuhan sekunder.

Konsumsi sebagai bagian kegiatan ekonomi yang bertujuan untuk memenuhi segala jenis kebutuhan baik itu kebutuhan barang maupu jasa.. Kebutuhan primer atau kebutuhan dasar adalah kebutuhan yang penting dalam menunjang kelangsungan hidup seseorang. Kebutuah primer terdiri dari kebutuhan konsumsi dan kebutuhan pelayanan social tertentu. Kebutuhan primer wajib dipenuhioleh seseorang agar dalam kehidupannya meraka mendapatkan kenyamanan secara individu dan sosial.

Manusia dalam kesehariannya akan selalu berusaha untuk dapat mencukupi kebutuhan secara berkelanjutan. Hal ini dikarenakan hakekat manusia yang tidak pernah mencapai kepuasan dalam capainnya kebutuhan mereka. Setelah kebutuhan satu tercapai, maka akan timbul keinginanbaru yang tentunya akan menjadi kebutuhan mereka. Dalam memenuhi kebutuhan konsimsinya, manusia akann menyisihkan kekayaannya. Faktorfaktor yang mendasari kegiatan konsumsi seseorang antara lain gaya hidup dan pendapatan (Ependi, 2013). Hasil penelitian yang disampaikan oleh Li et al (2019) menyatakan bahwa salah satu penyebab perubahan konsumsi adalah digital finance yang merupakan bagian dari lifestyle.

Tingkat konsumsi seseorang akan terus bertambah sebanding dengan meningkatnya pendapatan (income) yang diperolehnya. Akan tetapi hal ini tidak berlaku pada konsumsi jenis makanan. Pada batas tertentu dimana seseorang telah merasa sangat jenuh untuk melakukan konsumsi makanan maka penambahan penghasilan tidak dapat meningkatkan konsumsi pengeluaran makan secara signifikan. Hal ini memunculkan sebuah anggapan baru bahwa terdapat kecenderungan penurunan tingkat konsumsi jenis makanan pada seseorang ketika pendapatannya semakin meningkat. Namun, dalam hal konsumsi yang lain ini semakin meningkat (Aziz, 2009).

Penduduk Indonesia sekarang mempunyai gaya hidup sama seperti gaya hidup penduduk pada egara-negara maju. Hedonisme mengakibatkan 
menyebabkan penduduk Indonesia lebih bersikap konsumtif. Hal ini tentunya bertolak belakang dengan syariah islam yang lebih mengajarkan bahwa setiap orang harus dapat menahan diri supaya tidak terpengaruh oleh lingkungan sekitarnya yang menuju pada kegiatan konsumsi yang berlebihan. Pemerintah sebaiknya mampu mengedukasi masyarakat agar berperilaku, bertindak dan berfikir lebih praktis dan ekonomi seperti yang disyariahkan dalam islami, mengingat mayoritas penduduk Indonesia beragama islam. Jumlah penduduk muslim cukup banyak memudahkan setiap masyarakat Indonesia dalam melaksanakan nilai-nilai Islam, lingkungan yang Islami mampu membentengi seseorang dari perbuatan atau perilaku yang menyimpang dari ajaran Islam (Khozanah, 2014).

Pondok Modern Darussalam Gontor merupakan salah satu pondok yang berpengaruh di Indonesia, Gontor memiliki gaya hidup yang Islami dan ma'hadi serta tidak mudah terpengaruh oleh budaya luar yang tidak sesuai dengan syariat Islam seperti halnya yang banyak terlihat di zaman modern ini. Kegiatan yang ada di pondok semuanya tidak lepas dari arah dan tujuan pondok serta sesuai dengan nilai-nilai ajaran islam. Dengan adanya kegiatan tersebut membuat suasana yang dinamis dan memproteksi santri dari hal-hal yang tidak sesuai dengan alam pendidikan pondok.

\section{KAJIAN PUSTAKA}

\section{A. Konsumsi}

Ekonomi konvensional mengasumsikan bahwa tujuan dari konsumsi seseorang adalah untuk mencapai sebuah kepuasan (utility). Utility dapat diartikan sebagai berguna atau menolong atau menguntungkan (Arsyad, 2008). Menurut Suherman Rasyidi konsumsi adalah penggunaan barang danjasa untuk mencapai kepuasan kebutuhan manusia (the use of goods and service in thesatisfaction of human wants) (Rasyidi, 1998). Son (1993) mengemukakan "Konsumsi dirumuskan sebagai pengeluaran untuk barang dan jasa, seperti makan, pakaian, mobil, pengobatan dan perumahan.

Konsumsi adalah kegiatan menghabiskan utility ( nilai guna) barang dan jasa (Gordon, Gurrieri, \& Chapman, 2015). Barang konsumsi menurut kebutuhannya, yaitu: kebutuhan primer, kebutuhan sekunder, dan kebutuhan tersier (Son, 1993). Jadi, konsumsi menurut ekonomi konvensional adalah penggunaan atau pengeluaran barang dan jasa untuk memenuhi kebutuhan manusia baik jasmani maupun rumah tangga.

Al-Ghazali menyampaikan bahwa konsumsi adalah pemanfaatan barang dan jasa guna memenuhi kebutuhan melalui bekerja (al-iktisab) yang wajib dituntut (fardu kifayah) berpedoman etika (shariah) guna mencapai kemaslahatan (Chamid, 2010). Prinsip ekonomi islam mensyariatkan agar 
seseorang tidak hidup dalam kemewahan, bekerja pad atempat dan jenis pekerjaan yang dihalalkan, melakukan zakat dan menjauhi riba. Sistem ekoni islam merujuk pada akidah, akhlak dan syariat. Aktivitas seseorang baik itu individu maupun kolektif (social) harus bertumpu pada nilai moral islam. Seseorang secara individu dan sosial merupakan keniscayaan nilai yang harus hadir dalam pengembangan sistem, terlebih lagi ada kecenderungan nilai moral dan praktek yang mendahulukan kepentingan kolektif dibandingkan kepentingan individu. Preferensi ekonomi Islam memiliki karakter dengan bentuk aktifitas yang khas dan prinsip-prinsip dasar ekonomi Islam. Terdapat tiga aspek yaitu ketauhidan, khilafah, dan keadilan (Chapra, 2001).

\section{B. Pendapatan}

Dalam sebuah bisnis, pendapatan merupakan jumlah uang yang didapat atau diterima oleh perusahaan dari suatu aktivitasnya, hampir semua dari penjualan produk ataupun jasa kepada pelanggan. Dalam pertumbuhan suatu pendapatan adalah indikator yang penting dari penerimaan pasar dari sebuah produk dan jasa perusahaan tersebut. berikut pendapat para ahli:

Ikatan Akuntansi Indonesia (2009) menyatakan pendapatan ialah arus masuk bruto dari suatu kegiatan ekonomi yang timbul dari aktivitas normal sebuah perusahann dalam jangka waktu tertentu dalam satu periode. Apabila arus masuk tersebut menjadikan ekuitas meningkat yang tidak bersumber dari kontribusi penanaman modal. Sedangkan menurut (Tuanakota, 2000) pendapatan merupakan inflow of assets ke dalam perusahaan untuk akibat penjualan barang dan/atau jasa. Pendapatan merupakan penambahan aktiva yang dapat mengakibatkan bertambahnya modal namun bukan dikarenakan penambahan modal dari pemilik dan juga bukan merupakan hutang melainkan melalui penjualan barang dan jasa kepada pihak lain (Kusnadi, Maria, \& Irmadariyani, 2000).

Distribusi pendapatan dibahas dalam aspek ekonomi, aspek sosial dan aspek politik. Islam menganjurkan pengautnya untuk melakukan infak, zakat, shadaqah dan membantu kemasalhatan umat. Ajaran Islam tidak menganjurkan penyaluran atau pemanfaatan pendapatan yang sama dan rata dalam semua aspek atau kebutuhan. Antar orang mungkin mempunyai kebutuhan yang berbeda. Dalam memenuhi kebutuhan pribadipun seorang muslim harus mampu memberikan proporsi yang berbeda sesuai dengan kebermanfaatannya. Oleh sebab itu, sudah sepantasnya sebagai sesame umat, masyarakat dianjurkan untuk saling menolong, menghargai, menghormati, menyantuni bagi yang membutuhkan. 


\section{Gaya hidup}

Gaya hidup adalah sebuah pola hidup seseorang di dunia yang diekspresikan dalam aktivitas, minat, dan opininya. Gaya hidup menggambarkan "keseluruhan diri seseorang" dalam berinteraksi dengan lingkungannya (Kotler, 2002). Sedangkan menurut (Assael, 1984) gaya hidup adalah " $A$ mode of living that is identified by how people spend their time (activities), whatthey consider important in their environment (interest), and what they think of themselves and the world around them (opinions)". Gaya hidup menunjukkan bagaimana orang hidup, bagaimana membelanjakan uangnya, dan bagaimana mengalokasikan waktu (Mowen \& Minor, 2002).

Menurut (Kotler, 2002) adalah pola hidup seseorang di dunia yang diekspresikan dalam aktivitas, minat, dan opininya. Gaya hidup menggambarkan "keseluruhan diri seseorang" dalam berinteraksi dengan lingkungannya. Secara umum dapat diartikan sebagai suatu gaya hidup yang dikenali dengan bagaimana orang menghabiskan waktunya (aktivitas), apa yang penting orangpertimbangkan pada lingkungan (minat), dan apa yang orang pikirkan tentang diri sendiri dan dunia di sekitar (Amstrong, 2002).

Islam mengelompokkan gaya hidup menjadi dua bab yaitu gaya hidup jahii dan gaya hidup islami. Gaya hidup jahili Dalam pandangan Islam gaya hidup dapat dikelompokan menjadi dua yaitu gaya hidup Islami dan gaya hidup jahili. Gaya hidup jahili mempunyai sifat yang rapuh salah satunya adalah sifat syirik. Gaya hidup jahili merupakan gaya hidup pada zaman sebelum Nabi Muhammad SAW, yaitu pada masa kekafiran. Sedangkan gaya hidup islami adalah gaya hidup yang berlandaskan kekuatan dan kemutlakan Tauhid. Bagi setiap muslim mengikuti gaya hidup islami adalah suatu kewajiban.

\section{HIPOTESIS}

1. Pengaruh Pendapatan terhadap tingkat konsumsi Santri kelas 6 Pondok Modern Darussalam Gontor Kampus2

Pendapatan rumah tangga berpengaruh terhadap jumlah konsumsi. Apabila terjadi peningkatan pada nilai pendapatan, maka daya beli rumah tangga terhadap berbagai kebutuhan konsumsi akan semakin meningkat pula atau setidaknya semakin menuntut kualitas yang lebih baik (Wahab, 2012). Pendapatan yang berubah akan mampu menimbulkan perubahan pada berbagai permintaan barang dan jasa. Hal ini dapat disimpulkan bahwa tinggi rendahnya konsumsi masyarakat berasal dari pendapatan mereka sendiri.

$\mathrm{H}_{1}$ : Pendapatan berpengaruh terhadap tingkat konsumsi santri kelas 6 Pondok Modern Darussalam Gontor Kampus2. 
2. Pengaruh Gaya hidup terhadap tingkat konsumsi santri kelas 6 Pondok Modern Darussalam Gontor Kampus2

Faktor-faktor yang mendeterminasi Santri kelas 6 dalam mengambil keputusan untuk melakukan kegiatan konsumsi cukup banyak. Faktor internal dari pribadi setiap santri misalnya keinginan dalam diri sendiri. Selain faktor internal juga terdapat faktor eksternal seperti teman, orang tua dan lingkungan sekitar. Gaya hidup bagian dari faktor internal menjadi salah satu pengaruh yang cukup besar dalam penentuan seorang santri untuk melakukan konsumsi. Lifestyle atau gaya hidup adalah suatu cara pribadi seseorang dalam mendeskripsikan perilaku seseorang dalam memanfaatkan waktu dan harta yang dimilikinya.

$\left(\mathrm{H}_{2}\right)$ : Gaya Hidup berpengaruh terhadap tingkat konsumsi santri kelas 6 Pondok Modern Darussalam Gontor Kampus2.

\section{METODE}

Metode yang digunakan pada penelitian ini ialah analisis regresi linier berganda. Adapun variabel independen yaitu pendapatan dan gaya hidup. Sedangkan variabel respon yaitu tingkat konsumsi. Data penelitian diambil dari 20 santri kelas 6 pondok pesantren modern Gontor Kampus 2.

\section{HASIL DAN PEMBAHASAN \\ Karakteristik Subjek Penelitian}

Santri kelas 6 merupakan santri yang telah mencapai tingkatan akhir dalam jenjang pendidikan Kulliyatu-l- Muallimin al-Islamiyyah (KMI) di Pondok Modern Darussalam Gontor. Kelas 6 sudah mencapai tahapan santri senior, status mereka bukan merupakan anggota lagi namun sudah di anggap santri senior yang di percaya untuk memegang beberapa organisasi penting di pondok seperti, Organisasi Pelajar Pondok Modern dan Gerakan Pramuka.

Perbedaan antara santri kelas 6 dengan santri yang lain dapat dilihat secara signifikan dari bentuk kegiatan dan jumlah kegiatan di bidang akademis atau non-akademis yang bertujuan untuk menunjang kehidupan dan ilmu mereka untuk beramal di masyarakat. Kegiatan seperti Fathu-lKutub, Fathu-l- Mu'jam, Munaqosyah merupakan bentuk kegiatan akademis non-belajar di kelas setiap hari. Gerakan-gerakan kepramukaan, panitia dan organisasi, dan sebagainya merupakan kegiatan non-akademis yang membantu santri kelas 6 untuk menemukan talenta dan masing-masing untuk berkembang.

Kehidupan kelas 6 mempunyai kehidupan yang berbeda, mereka tidak dibawahi oleh pengurus kelas 5 melainkan mereka dibawahi langsung oleh staff Pengasuhan Santri dan staff guru-guru lainnya. Bahkan sebagian dari 
mereka ada yang mengelola organisasi dan mengelola jadwal santri, sehingga kehidupan mereka tidak terlalu di awasi dan tidak terlalu dikekang seperti santri lainnya.

\section{Analisi Data Penelitian}

Hasil olah data penelitian ditunjukkan pada Tabel 1. Nilai koefisien regresi pada variabel pendapatan (X1) adalah 1.671; artinya apabila variabel independen yang lain (dalam hal ini adalah variabel gaya hidup) bernilai konstan dan variabel pendapatan mengalami kenaikan 1\%, maka tingkat konsumsi akan meningkat Rp. 1,671. Koefisien regresi mempunyai nilai positif artinya terjadi hubungan positif antara pendapatan dengan konsumsi. Semakin tinggi pendapatan maka semakin tinggi tingkat konsumsi.

Nilai koefisien pada variabel gaya hidup (X2) adalah 4006,462; yang berarti apabila variabel independen lainnya bernilai konstan (dalam hal ini adalah variabel pendapatan) dan variabel gaya hidup mengalami kenaikan sebesar 1\%, maka konsumsi (Y) dapat meningkat sebanyak Rp. 4006,462. Akan tetapi nilai signifikansi pada variabel gaya hidup menunjukkan 0,389 yang artinya gaya hidup tidak berpengaruh terhadap konsumsi secara signifikan.

Tabel. 1 Hasil Analisis Regresi Linear Berganda

\begin{tabular}{llllcl}
\hline Model & & $\begin{array}{l}\text { Unstandardized } \\
\text { Coefficients }\end{array}$ & $\begin{array}{l}\text { Standardized } \\
\text { Coefficients }\end{array}$ & t & Sig. \\
\hline & \multicolumn{1}{c}{$\mathrm{B}$} & \multicolumn{1}{c}{ Std. Error } & Beta & $\mathrm{B}$ & Std. Error \\
\hline (Constant) & -60343.824 & 215442.324 & & -.280 & .783 \\
\hline pendapatan & 1.671 & .106 & .973 & 15.813 & .000 \\
\hline gaya_hidup & 4006.462 & 4532.421 & .054 & .884 & .389 \\
\hline
\end{tabular}

Sumber: Data diolah

\section{Analisis Korelasi dan Determinasi}

Analisis korelasi (R) meruakan suatu analisis yang bertujuan untuk mengetahui hubungan dari dua atau lebih variabel. Dalam analisis korelasi tidak menyebutkan variabel independen dan variabel dependen. Nilai korelasi (R) adalah 0 sampai dengan 1 . Apabila nilai $\mathrm{R}$ mendekati 1 maka artinya terjadi hubungan yang sangat kuat, sebaliknya jika nilai $\mathrm{R}$ mendekati 0 maka korelasi atau hubungan antar variabel semakin lemah. Selain itu, nilai korelasi bisa juga bernilai positif dan juga negatif. Nilai R bernilai positif artinya terjadi hubungan yang sebanding, sebaliknya nilai $\mathrm{R}$ negative atinya terjadi hubungan yang berbanding terbalik. Hasil analisis korelasi ditunjukkan pada Tabel 2. sebagai berikut: 
Andi Triyawan: Determinan Tingkat Konsumsi

\begin{tabular}{llcc}
\multicolumn{4}{l}{ Tabel 2. Hasil Analisis Korelasi Ganda } \\
\hline Model & R & R Square & $\begin{array}{l}\text { Adjusted } \\
\text { R Square }\end{array}$ \\
\hline & .968 & .937 & .929 \\
\hline
\end{tabular}

Sumber: Data diolah

Berdasarkan Tabel 2. didapatkan nilai R 0,968. Hal ini menunjukkan bahwa terjadi hubungan yang sangat kuat antara pendapatan dan gaya hidup terhadap konsumsi (Sugiyono, 2007). Analisis determinasi (R ${ }^{2}$ ) dalam regresi linear berganda digunakan untuk mengetahui seberapa besar persentase variasi variabel independen mampu menjelaskan variasi variabel dependen. $\mathrm{R}^{2}$ sama dengan 0 , maka tidak ada sedikitpun prosentase sumbangan pengaruh yang diberikan variabel independen terhadap variabel dependen, atau variasi variabel independen yang digunakan dalam model tidak menjelaskan sedikitpun variasi variabel dependen. Sebaliknya $\mathrm{R}^{2}$ sama dengan 1, maka prosentase sumbangan pengaruh yang diberikan variabel independen terhadap variabel dependen adalah sempurna, atau variasi variabel independen yang digunakan dalam model menjelaskan $100 \%$ variasi variabel dependen.

Berdasarkan Tabel 2. diperoleh angka $\mathrm{R}^{2}$ sebesar 0,937 atau $(93,7 \%)$. Hal ini menunjukkan bahwa variabel independen (pendapatan dan gaya hidup) mampu menjelaskan sebesar 93,7\% terhadap variasi variabel dependen (konsumsi). Sedangkan sisanya sebesar 6,3\% dipengaruhi atau dijelaskan oleh variabel lain yang tidak dimasukkan dalam model penelitian ini.

\section{Uji Koefisien Regresi Secara Simultan (Uji F)}

Uji ini digunakan untuk mengetahui model regresi dapat digunakan untuk memprediksi variabel dependen atau tidak. Signifikan berarti hubungan yang terjadi dapat berlaku untuk populasi (dapat digeneralisasikan), misalnya dari kasus di atas populasinya adalah 200 santri kelas 6 dan sampel yang diambil dari kasus di atas 20 santri, jadi apakah pengaruh yang terjadi atau kesimpulan yang didapat berlaku untuk populasi yang berjumlah 200 santri kelas 6 .

Tabel 3. Hasil Uji F

\begin{tabular}{lll}
\hline Model & F & Sig. \\
\hline Regression & 253.451 & .000 \\
\hline Residual & & \\
\hline \multicolumn{1}{c}{ Total } & \\
\hline Regression & 125.577 & .000 \\
\hline Residual & \\
\hline Total & \\
Sumber: Data diolah &
\end{tabular}


Berdasarkan nilai signifikansi pada Tabel 3. sebesar 0.000, maka dapat disimpulkan bahwa pendapatan dan gaya hidup secara simultan mampu mempengaruhi tingkat konsumsi santri kelas 6 PMDG kampus 2.

\section{KESIMPULAN}

Dari penelitian ini dapat di simpulkan bahwa tingkat konsumsi santri kelas 6 PMDG kampus 2 dipengaruhi oleh pendapatan dan gaya hidup secara simultan. Sedangkan secara parsial, gaya hidup tidak berpengaruh positif terhadap tingkat konsumsi santri kelas 6 PMDG kampus, namun pendapatan berpengaruh positif terhadap tingkat konsumsi santri kelas 6 PMDG kampus

\section{DAFTAR PUSTAKA}

Amstrong, Gary \& Kotler. (2002) Dasar-Dasar Pemasaran. Jakarta: Prenhalindo.

Antonio, M Syafi'i. (2001). Bank syariah dari Teorika Praktek. Jakarta: Gema Insani Press.

Arsyad, Lincolin. (2008). Ekonomi Manajerial. Yogyakarta: PBEF-Yogyakarta.

Assael, H. (1984). Consumer Behavior and Marketing Action. Boston: Kent Publishing Company.

Azis, Muhammad Abdul. (2009). Analisis Faktor-faktor Yang Mempengaruhi Konsumsi Masyarakat di Provinsi Jawa Tengah Tahun 2003-2007. Surakarta: Universitas Selebes Maret.

Chamid, Nur. (2010). Jejak Langkah Sejarah Pemikiran Ekonomi Islam. Yogyakarta: Pustaka Pelajar.

Chapra, Umer. (2001). Masa Depan Ilmu Ekonomi. Jakarta: Gema Insani Press.

Ependi. (2013). Pengaruh Pendapatan dan Gaya Hidup Terhadap Perilaku Konsumsi Masyarakat. Bandung: Universitas Pendidikan Indonesia.

Gordon, R., Gurrieri, L., \& Chapman, M. (2015). Broadening an Understanding of Problem Gambling: The Lifestyle Consumption Community of Sport Betting. Journal of Business Research , 2164-2172.

Indonesia, I. A. (2009). Standar Akuntansi Keuangan. Jakarta: Salemba Empat. Khozanah, Ummi. (2014). Analisis Faktor-Faktor Yang Mempengaruhi Pola Konsumsi Dalam Pandangan Islam (Survei Pada Pengurus dan Anggota Asbisindo di Jawa Barat). Bandung: Universitas Pendidikan Indonesia.

Kotler, P. (2002). Manajemen Pemasaran: Edisi Milenium. Jakarta: PT. Prehalindo.

Kusnadi, Maria, S., \& Irmadariyani, R. (2000). Akuntansi Keuangan Menengah: Prinsip, Prosedur, dan Metode. Jakarta: Salemba Empat.

Li, J., Wu, Y., \& Xiao, J.J. (2019). The Impact of Digital Finance on Household Consumption: Evidence From China. Economic Modelling Journal.

Mowen, J. C., \& Minor, M. (2002). Perilaku Konsumen. Jakarta: Erlangga.

Rasyidi, Suherman. (1998). Pengantar Teori Ekonomi: Pendekatan Kepada Teori Ekonomi Mikro dan Makro. Jakarta: PT. Raja Grafindo. 
Son, P. S., \& William, D. N. H. (1993). Ekonomi, Jilid. 1. Jakarta: Erlangga.

Sugiyono. (2007). Metode Penelitian Bisnis. Jakarta: Gramedia.

Tuanakota, T. M. (2000). Teori Akuntansi. Jakarta: Salemba Empat.

Wahab, H. Abdul. (2012). Pengantar Ekonomi Makro. Cetakan I. Makassar: Alauddin University Press. 